\title{
Efektivitas Pengolahan Air Limbah Domestik Grey Water Dengan Proses Biofilter Anaerob dan Biofilter Aerob (Studi Kasus: IPAL INBIS Permata Bunda, Bontang)
}

\author{
Muhammad Busyairi $^{{ }^{*}}$, Nikita Adriyanti ${ }^{2}$, Abdul Kahar ${ }^{3}$, Dian Nurcahya ${ }^{4}$, Sariyadi $^{5}$, \\ Tathok D Hudayana ${ }^{6}$ \\ ${ }^{1,3,5,6}$ Program Studi Teknik Lingkungan, Fakultas Teknik, Universitas Mulawarman \\ Jalan Sambaliung No.9 Samarinda, Kalimantan Timur, Indonesia \\ ${ }^{2,4}$ Departemen Corporate Social Responsibility, PT. Pupuk Kaltim, \\ Kota Bontang, Kalimantan Timur, Indonesia \\ *Koresponden email: busyairi22@gmail.com
}

Diterima: 16 September 2020

Disetujui: 2 Oktober 2020

\begin{abstract}
Domestic wastewater from non toilets is referred to as grey wastewater, domestic wastewater from bathing, washing and from the kitchen. Incubator Bisnis (INBIS) Permata Bunda is a forum for the application of entrepreneurial skills (apprenticeship) for people with disabilities residing in Kampung Aren, Bontang City, East Kalimantan. Grey wastewater treatment at INBIS Permata Bunda with a grease trap, filtration, sedimentation, anaerobic biofilter, aerobic biofilter, sedimentation and control. The research objective was to determine the effectiveness of INBIS Domestic WWTP to reduce organic pollutant loads based on the quality standard parameters of domestic wastewater from the Minister of Environment and Forestry Regulation No.P.68 of 2016 those are the parameters of pH, BOD, COD, TSS, fatty oil, ammonia, and total coliform. The domestic wastewater treatment process for grey wastewater has a reduced effectiveness ranging from $56.73 \%-97.65 \%$ and has met the quality standards for the parameters, $\mathrm{pH}, \mathrm{BOD}, \mathrm{COD}$, ammonia, fatty oil, and total coliform, but for TSS parameters and total coliform needs operational evaluation. Grey waterwater from the INBIS domestic wastewater treatment plant has the potential to become an alternative water source for watering plants (afforestation) if the processing results are in accordance with quality standards.
\end{abstract}

Keywords: biofilter anaerob, biofilter aerob, grey water, inkubator bisnis, Kampung Aren

\begin{abstract}
Abstrak
Air limbah domestik non toilet/kakus disebut sebagai grey water, yang merupakan air limbah domestik berasal dari air mandi, air cuci dan air dari dapur. Inkubator Bisnis (INBIS) Permata Bunda merupakan wadah pengaplikasian keterampilan wirausaha bagi penyandang disabilitas yang berada di Kampung Aren Kota Bontang Kaltim. Pengolahan air limbah domestik grey water pada INBIS Permata Bunda dengan unit pengolahan pemisah lemak (grease trap), filtrasi, sedimentasi, biofilter anaerob, biofilter aerob, sedimentasi akhir dan bak kontrol. Tujuan penelitian untuk mengetahui efektivitas IPAL Domestik INBIS untuk mereduksi beban pencemar organik berdasarkan parameter baku mutu limbah domestik dari Peraturan Menteri Lingkungnan Hidup dan Kehutanan No.P.68 Tahun 2016 yaitu parameter pH, BOD, COD, TSS, Minyak Lemak, Amoniak dan Total Coliform. Proses pengolahan air limbah domestik untuk air limbah grey water memiliki efektivitas reduksi berkisar antara 56,73\% - 97,65\% dan telah memenuhi baku mutu untuk parameter, pH, BOD, COD, Amoniak, Minyak Lemak dan Total Coliform, namun untuk parameter TSS dan Total Coliform perlu evaluasi operasional. Air limbah domestik grey water dari hasil pengolahan IPAL Domestik INBIS berpotensi menjadi sumber air alternatif untuk penyiraman tanaman (penghijauan) jika hasil pengolahan telah sesuai dengan baku mutu.
\end{abstract}

Kata Kunci: biofilter anaerob, biofilter aerob, limbah domestik non toilet, inkubator bisnis, Kampung Aren

\section{Pendahuluan}

Fasilitas tempat tinggal, penyediaan air bersih dan fasilitas air buangan/limbah domestik merupakan indikator status kesehatan lingkungan pemukiman masyarakat atau disebut sanitasi lingkungan [1]. Permasalahan umum kondisi sanitasi tersebut adalah $46,7 \%$ berasal dari fasilitas limbah 
domestik rumah tangga dan berpotensi mencemari perairan umum [2]. Kebutuhan air yang berhubungan dengan aktivitas hidup sehari-hari manusia merupakan sumber air limbah domestik [3] tentang Baku Mutu Air Limbah Domestik.

Kontribusi air limbah domestik dari rumah tangga terhadap pencemaran air permukaan adalah $78,9 \%$, untuk wilayah komersil/toko dan perkantoran $13,1 \%$, dan kontribusi air limbah dari industri $8 \%$, beban pencemar untuk polutan organik terbesar adalah 73,4\% yang berasal dari rumah tangga [4]. Air limbah domestik non toilet/kakus disebut sebagai grey water, yang merupakan air limbah domestik berasal dari air mandi, air cuci dan air dari dapur [5]. Inkubator Bisnis (INBIS) Permata Bunda merupakan wadah pengaplikasian keterampilan wirausaha (magang) bagi penyandang disabilitas yang berada di Kampung Aren Kota Bontang Kaltim. Melalui program magang/pelatihan INBIS Permata Bunda diharapkan penyandang disabilitas yang merupakan lulusan dari Sekolah Luar Biasa di Kota Bontang dapat mandiri dalam dan ikut berperan untuk pemenuhan kebutuhan kerja. Aktivitas INBIS Permata Bunda merupakan lanjutan pendidikan siap kerja non formal bagi penyandang disabilitas pasca SLB.

Kebutuhan air bersih untuk mendukung operasional INBIS Permata Bunda bersumber dari air PDAM, dengan kebutuhan rata-rata adalah $53,25 \mathrm{~m}^{3} /$ perbulan. Air bersih yang telah menjadi air limbah tersebut berpotensi mencemari Sungai Api-Api yang berada disisi selatan dari INBIS Permata Bunda dan potensi pencemaran tersebut berasal dari limbah domestik grey water. Pengolahan limbah cair domestik atau grey water pada INBIS Permata Bunda telah dilengkapi IPAL (Instalasi Pengolahan Air Limbah) dengan unit pengolahan pemisah lemak (grease trap), filtrasi, sedimentasi, biofilter anaerob, biofilter aerob, sedimentasi akhir, dan bak kontrol, dengan kombinasi proses pengolahan air limbah secara fisik, biologi dan kimia.

Hasil pengolahan air limbah domestik grey water merupakan sumber alternatif untuk memenuhi kebutuhan air untuk penyiraman/penghijauan tanaman, selain itu mengurangi volume dan beban pencemar air limbah yang mengalir ke sistem drainase kota atau badan air permukaan/sungai [6]. Fasilitas pengolahan air limbah domestik berupa IPAL pada lokasi INBIS Permata Bunda merupakan solusi untuk mengatasi pencegahan pencemaran air limbah domestik ke Sungai Api-Api dan sebagai upaya untuk pemanfaatan kembali air limbah (reuse) untuk keperluan penghijauan atau penyiraman tanaman pada lingkungan INBIS Permata Bunda dan Kampung Aren. Pengolahan air limbah dengan biofilter anaerob dan biofilter aerob atau kombinasi keduanya cukup efektif untuk mereduksi kadar organik limbah seperti BOD, COD, TSS, Amoniak, TDS dan Total Coliform dengan biaya operasional yang terjangkau [7].

Penelitian ini bertujuan untuk mengetahui efektivitas IPAL Domestik INBIS untuk mereduksi beban pencemar organik (\% removal) berdasarkan parameter baku mutu limbah domestik dari PerMenLHK No.P.68 Tahun 2016 yaitu parameter pH, BOD, COD, TSS, Minyak Lemak, Amoniak, dan Total Coliform.

\section{Metodologi Penelitian \\ Tempat dan Metode Penelitian}

Lokasi penelitian berada di Instalasi Pengolahan Air Limbah (IPAL) Domestik grey water Inkubator Bisnis (INBIS) Permata Bunda, Jalan A. Yani No.13 RT.22 Gang Aren/ Kampung Aren, Kelurahan Api-Api, Kecamatan Bontang Utara, Kota Bontang-Kaltim.

Berdasarkan metode pengambilan contoh air limbah [8], maka lokasi pengambilan air limbah yang bertujuan untuk mengetahui efektivitas pengolahan air limbah domestik grey water dari IPAL Domestik INBIS dilakukan pada inlet atau sebelum air limbah masuk ke bak filtrasi, untuk lokasi titik pengambilan sampel selanjutnya sebagai perbandingan dilakukan pada outlet atau bak terakhir dari rangkaian unit pengolahan air limbah. Lokasi pengambilan sampel air limbah dapat dilihat Gambar 1.

\section{Prosedur}

Sampel air limbah pada inlet dan outlet dari IPAL dengan masing-masing volume 5 liter, selanjutkan dianalisis pada Laboratorium Penguji PT Pupuk Kaltim untuk setiap parameter berdasarkan baku mutu air limbah domestik. Hasil analisis laboratorium tersebut akan dilakukan perhitungan efesiensi reduksi beban pencemar untuk masing-masing parameter dalam air limbah domestik hasil pengolahan. Hasil perhitungan akan dibandingkan dengan baku mutu air limbah domestik yaitu PerMenLHK No.P.68 Tahun 2016. 


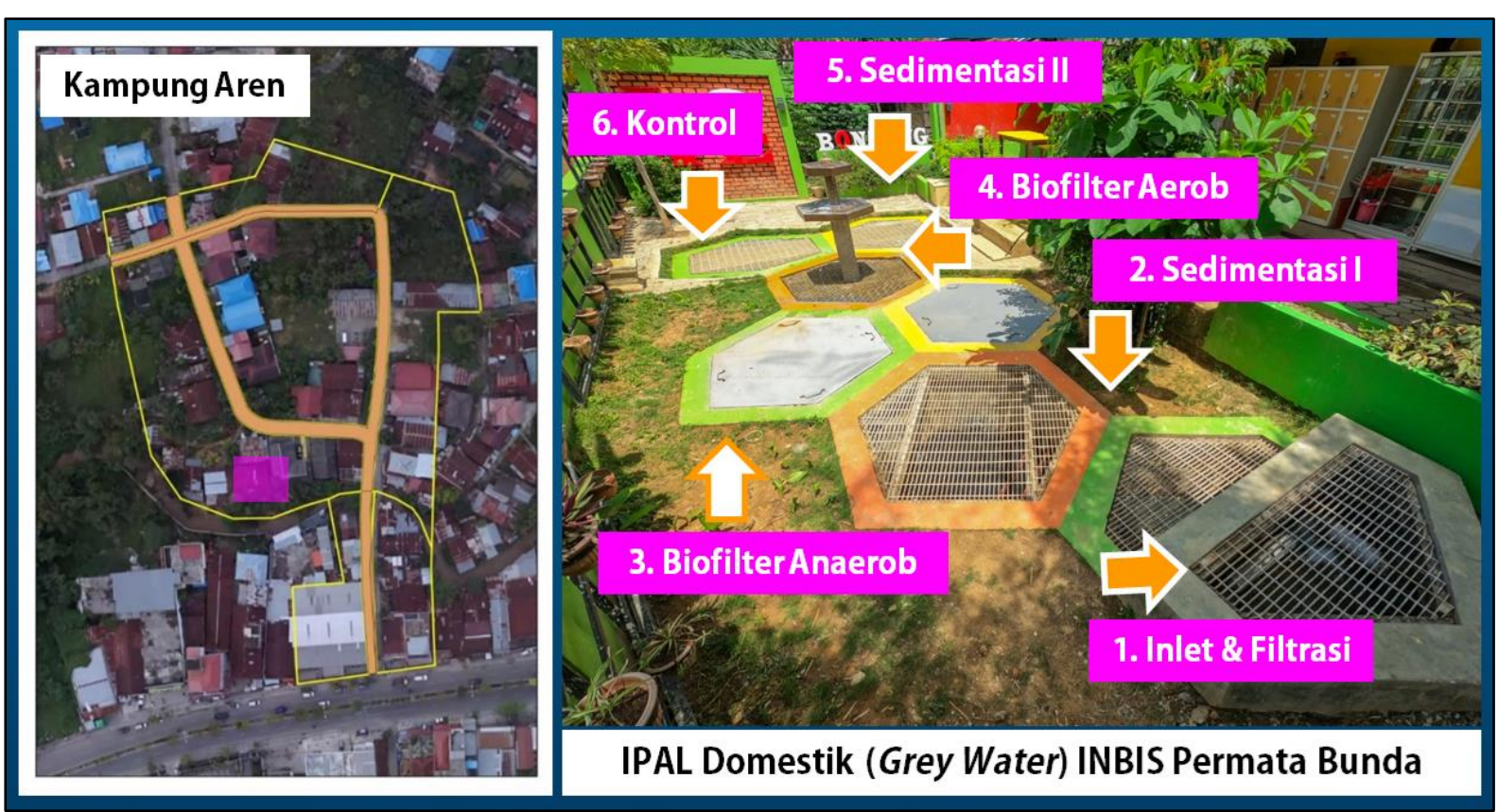

Gambar 1. Lokasi IPAL domestik (Grey Water) INBIS di Kampung Aren dan lokasi titik sampling inlet dan outlet/bak kontrol

Sumber: Data primer, 2020

Hasil analisis dan perbandingan baku mutu tersebut akan diketahui efektifitas IPAL Domestik INBIS, pendekatan efektifitas IPAL Domestik INBIS dengan menggunakan rumus efisiensi sebagai berikut [9]:

$$
\mathrm{E}=\frac{C o-C i}{C o} \times 100 \%
$$

$$
\begin{array}{ll}
\text { Dimana } & \mathrm{E}=\text { Efisiensi }(\%) \\
& \mathrm{Co}=\text { Konsentrasi Inlet IPAL } \\
& \mathrm{Ci}=\text { Konsentrasi Outlet IPAL }
\end{array}
$$

\section{Hasil dan Pembahasan}

\section{Analisis Kualitas Air Limbah}

Berdasarkan dari hasil analisis Laboratorium Penguji PT Pupuk Kaltim pada titik inlet dan outlet IPAL Domestik INBIS diperoleh hasil pada Tabel 1.

Tabel 1. Hasil analisis kualitas air limbah

\begin{tabular}{lcccc}
\hline \multicolumn{1}{c}{ Paramater } & Satuan & Baku Mutu & $\begin{array}{c}\text { Air Limbah } \\
\text { (Inlet) }\end{array}$ & $\begin{array}{c}\text { Air Limbah } \\
\text { (Outlet) }\end{array}$ \\
\hline $\mathrm{pH}$ & - & $6-9$ & 5,71 & 7,31 \\
$\mathrm{BOD}$ & $\mathrm{mg} / \mathrm{L}$ & 30 & 145 & 23,4 \\
$\mathrm{COD}$ & $\mathrm{mg} / \mathrm{L}$ & 100 & 1495 & 62,9 \\
$\mathrm{TSS}$ & $\mathrm{mg} / \mathrm{L}$ & 30 & 141 & 61 \\
Minyak Lemak & $\mathrm{mg} / \mathrm{L}$ & 5 & 26,6 & 0,625 \\
Amoniak & $\mathrm{mg} / \mathrm{L}$ & 10 & $*$ & 1,14 \\
Total Coliform & Jumlah/100ml & 3000 & 2419,6 & 2419,6 \\
\hline \multicolumn{5}{c}{ Sumber : Data primer, 2020 } \\
\\
\multicolumn{5}{c}{ Ket: *titik inlet tidak dilakukan analisis $\mathrm{NH}_{3}$} \\
\end{tabular}

Berdasarkan Tabel 1 menunjukkan bahwa analisis parameter $\mathrm{pH}$ dari hasil pengolahan air limbah dari kondisi asam pH 5,71 menjadi netral pH 7,31 pada outlet IPAL dan telah sesuai dengan baku mutu. Paramater Amoniak $\left(\mathrm{NH}_{3}\right)$ pada outlet hasil pengolahan adalah $1,14 \mathrm{mg} / \mathrm{L}$ (nilai baku mutu $10 \mathrm{mg} / \mathrm{L}$ ) atau telah sesuai dengan baku mutu (titik inlet tidak dilakukan analisis $\mathrm{NH}_{3}$ ), kondisi amoniak pada grey water yang telah sesuai dengan baku mutu karena polutan organik pada bak biofilter aerob akan menjadi gas, amoniak teroksidasi menjadi nitrit dan nitrat. 
Sementara itu, total coliform pada inlet dan outlet hasil pengolahan IPAL adalah sebesar 2419,6 $\mathrm{mg} / \mathrm{L}$. Nilai tersebut cenderung sudah sesuai dengan nilai baku mutu yaitu $3000 \mathrm{mg} / \mathrm{L}$. Karakteristik limbah domestik grey water berbeda dengan black water untuk kandungan total coliform, namun sebagai bahan evaluasi IPAL Domestik INBIS diharapkan dilengkapi dengan proses klorinasi menggunakan klorin sebagai disinfektan. Proses klorinasi bisa diletakkan untuk melengkapi bak kontrol pada akhir proses dimana proses klorinasi merupakan inaktivasi pathogen atau bakteri. Penggunaan klorin yang mudah larut dalam air dan efektivitas reduksi total coliform bisa mencapai 98\%, penggunaan klorin sebagai disinfektan perlu memperhatikan residu klor yang dihasilkan [10].

Parameter BOD umumnya memiliki nilai yang lebih rendah dari COD, nilai BOD pada air limbah menunjukkan jumlah oksigen terlarut yang dibutuhkan oleh mikroba untuk mendegradasi/mengoksidasi atau bahan organik sebagai bahan pencemar. Sedangkan nilai COD yang lebih tinggi dari BOD karena beban pencemar senyawa kimia yang dapat dioksidasi secara kimia lebih besar dari pada oksidasi secara biologis [9]. Kualitas inlet parameter BOD dan COD pada Tabel 1 menunjukkan nilai yang melebihi baku mutu, nilai BOD dan COD yang tinggi atau melebihi baku mutu menunjukkan tingkat pencemaran kualitas air limbah [11]. Efektivitas proses pengolahan pada IPAL Domestik INBIS dengan dengan kombinasi biofilter anaerob dan biofilter aerob untuk parameter BOD dan COD pada inlet dan outlet dapat dilihat pada Gambar 2.

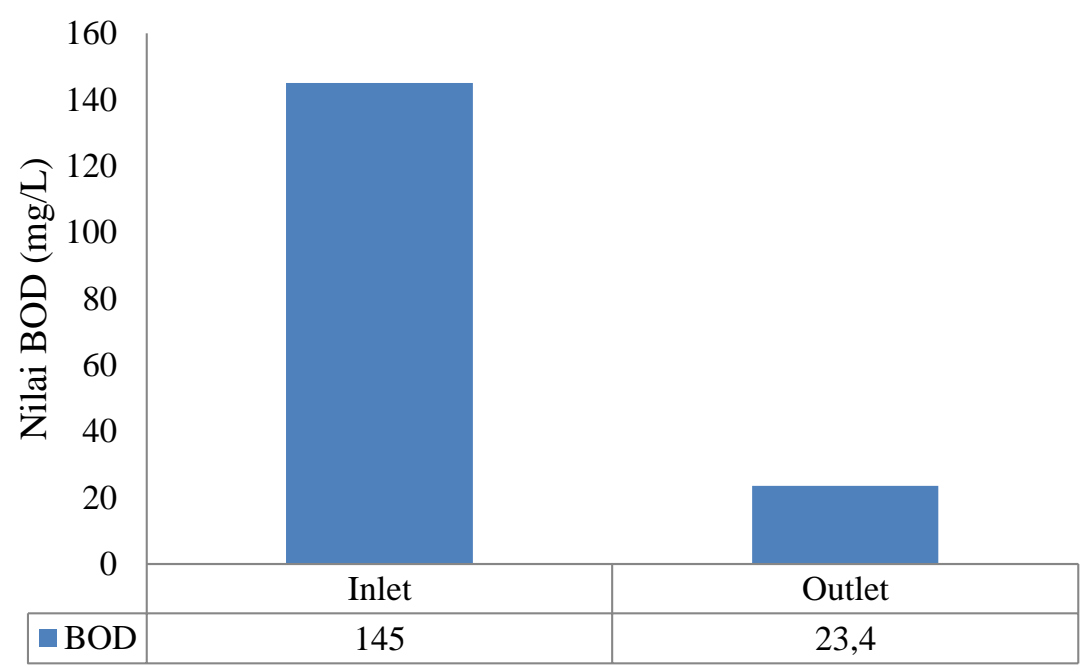

Gambar 2. Efektivitas proses pengolahan IPAL domestik (grey water) INBIS di Kampung Aren terhadap parameter BOD Sumber: Data primer, 2020

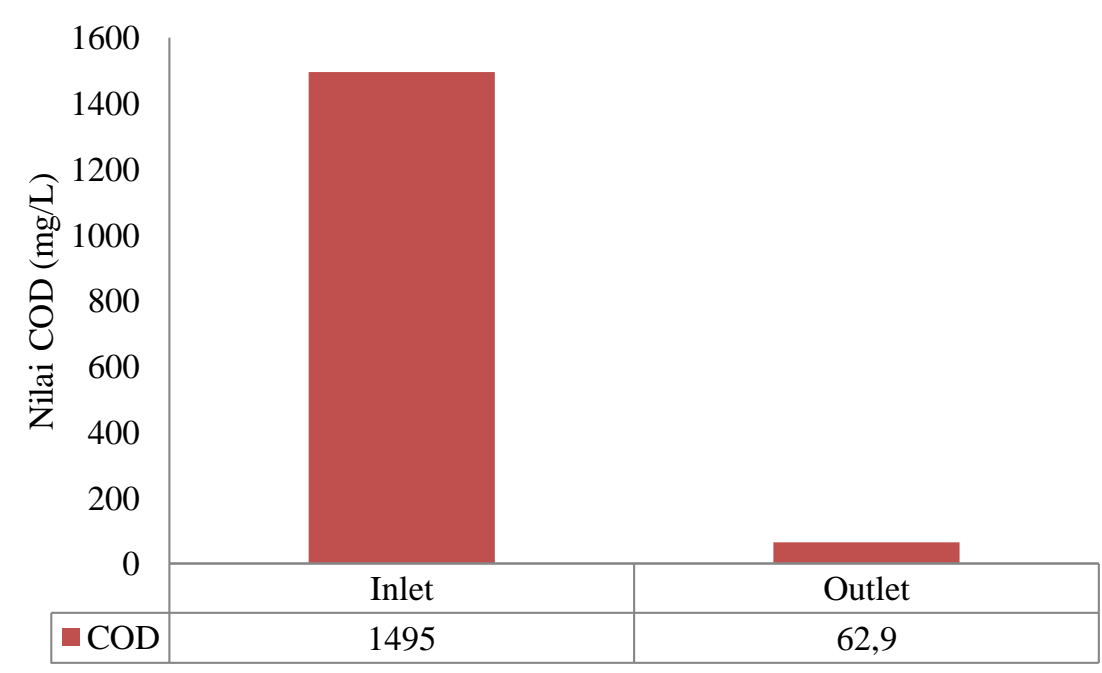

Gambar 3. Efektivitas proses pengolahan IPAL domestik (grey water) INBIS di Kampung Aren terhadap parameter COD Sumber: Data primer, 2020 
Efektivitas proses pengolahan air limbah domestik grey water pada IPAL Domestik INBIS untuk parameter BOD adalah $83,86 \%$ dan untuk parameter COD adalah 96,79\%. Efektivitas proses pengolahan berbanding lurus dengan pemenuhan baku mutu air limbah sesuai dengan PerMenLHK No.P.68 Tahun 2016. Nilai parameter BOD pada outlet IPAL adalah $23,4 \mathrm{mg} / \mathrm{L}$ dengan nilai baku mutu $30 \mathrm{mg} / \mathrm{L}$, sedangkan untuk parameter COD nilai pada outlet IPAL adalah $62,9 \mathrm{mg} / \mathrm{L}$ dengan nilai baku mutu 100 $\mathrm{mg} / \mathrm{L}$. Parameter TSS merupakan parameter visual yang menyebabkan kekeruhan pada air limbah. Nilai TSS dengan konsentrasi tinggi mempengaruhi penetrasi sinar matahari pada perairan sehingga mengganggu proses fotosintesis [12], bahan organik pada air limbah yang menyebabkan kekeruhan terdiri dari senyawa selulosa, lemak, protein atau berupa mikroorganisme [13].

Parameter minyak lemak merupakan karakteristik organik pada air limbah domestik, tumpukan minyak pada unit pengolahan dapat menyebabkan sumbatan saluran. Minyak lemak umumnya berasal dari dapur pada setiap kegiatan rumah tinggal, minyak lemak merupakan bahan organik yang bersifat biodegradable sehingga keberadaannya pada perairan umum dapat membahayakan kehidupan mikroorganisme lain dalam air [14]. Efektivitas proses pengolahan pada IPAL Domestik INBIS dengan kombinasi proses filtrasi dan sedimentasi pada inlet dan outlet untuk parameter TSS dan minyak lemak dapat dilihat pada Gambar 4.

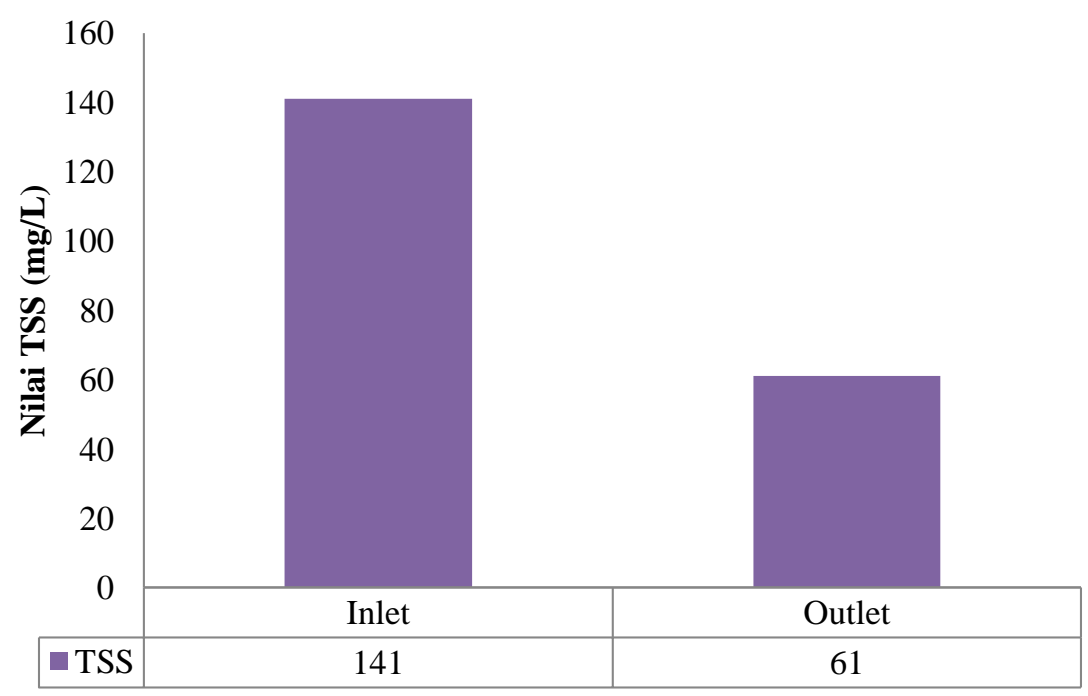

Gambar 4. Efektivitas proses pengolahan IPAL domestik (grey water) INBIS di Kampung Aren terhadap parameter TSS Sumber: Data primer, 2020

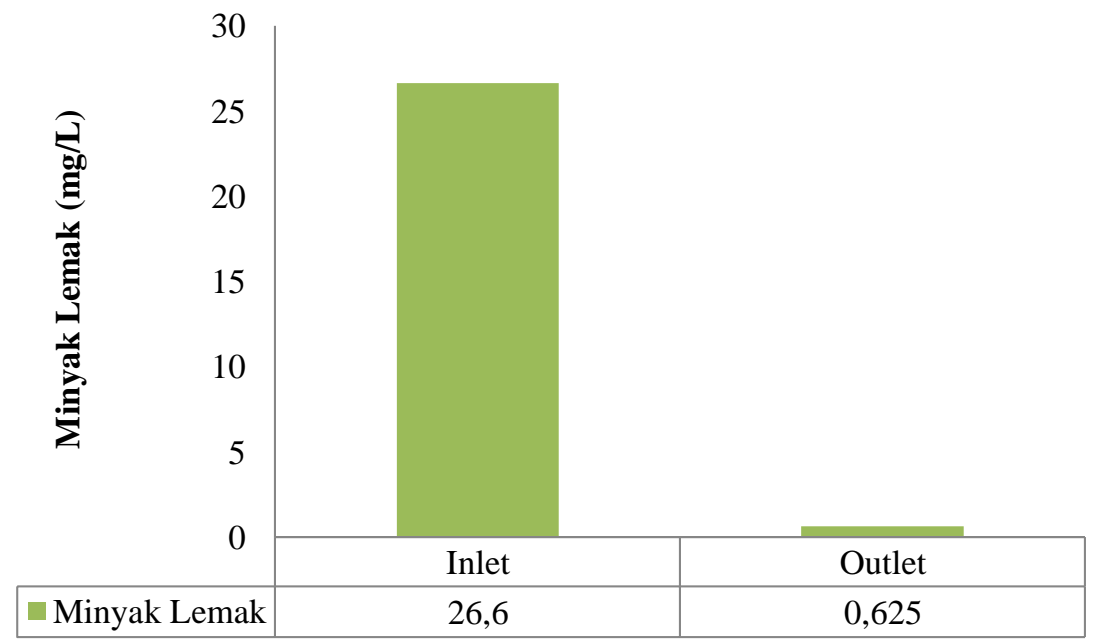

Gambar 5. Efektivitas proses pengolahan IPAL domestik (Grey Water) INBIS di Kampung Aren terhadap parameter minyak lemak Sumber: Data primer, 2020 
Efektivitas proses pengolahan air limbah domestik grey water pada IPAL Domestik INBIS untuk parameter TSS adalah 56,73\% dan untuk parameter Minyak Lemak adalah 97,65\%, efektivitas proses pengolahan berbanding lurus dengan pemenuhan baku mutu air limbah sesuai dengan PerMenLHK No.P.68 Tahun 2016, untuk parameter Minyak Lemak nilai pada outlet IPAL adalah 0,625 mg/L dengan nilai baku mutu $5 \mathrm{mg} / \mathrm{L}$, sedangkan untuk parameter TSS nilai pada outlet IPAL adalah $61 \mathrm{mg} / \mathrm{L}$ dengan nilai baku mutu $30 \mathrm{mg} / \mathrm{L}$, indikator parameter TSS hasil pengolahan masih belum memenuhi baku mutu yang dipersyaratkan. Efektivitas dari nilai TSS yaitu 56,73\% masih dapat ditingkatkan sehingga dapat memenuhi baku mutu dengan cara mengevaluasi ketebalan media filter pada filtrasi, waktu tinggal (waktu pengendapan) pada sedimentasi akhir dapat menjadi optimal.

\section{Analisis Pengolahan IPAL}

Proses pengolahan air limbah domestik pada IPAL Domestik INBIS Permata Bunda untuk air limbah grey water memiliki efektivitas reduksi berkisar antara 56,73\%-97,65\%. Efektivitas tertinggi ditunjukkan oleh parameter minyak lemak dan yang terendah adalah parameter TSS. Efektivitas untuk parameter minyak lemak didukung dari proses pemisahan minyak lemak menggunakan grease trap pada saluran pembawa limbah menuju inlet IPAL yang bekerja optimal. Optimalisasi grease trap telah terbukti mampu memisahkan minyak lemak pada air limbah dengan memanfaatkan massa jenis minyak lemak yang lebih ringan dari pada air (minyak $0,8 \mathrm{~m}^{3} / \mathrm{g}$, lemak $0,8-0,9 \mathrm{~m}^{3} / \mathrm{g}$, dan air $1 \mathrm{~m}^{3} / 9$ ) [14].

Efektivitas parameter TSS pada IPAL Domestik INBIS cenderung belum mencapai optimal atau belum memenuhi standar baku mutu. Namun demikian, dapat ditingkatkan dengan cara menambah ketebalan media filter (serabut sapu ijuk, kerikil dan arang aktif) pada bak filtrasi dan menambah waktu tinggal pada bak sedimentasi akhir. Penambahan media filter dan waktu tinggal pada bak sedimentasi berbanding lurus dengan penurunan nilai TSS [15].

Pengolahan air limbah domestik dengan reaktor biologis menggunakan proses biofilter anaerob media sarang tawon lalu dilanjutkan dengan proses biofilter aerob menggunakan blower (aerasi) memiliki nilai efektivitas untuk parameter BOD adalah 83,86\% dan untuk parameter COD adalah $96,79 \%$. Nilai efektivitas kedua parameter tersebut dalam menurunkan beban pencemaran menunjukkan persentase diatas $80 \%$. Hal ini menunjukkan bahwa hasil pengolahan pada outlet IPAL telah sesuai dengan baku mutu yang dipersyaratkan.

Proses biologis pada bak biofilter anaerob memberikan kesempatan secara alami untuk perkembangbiakan mikroorganisme yang melekat pada permukaan media (biofilm), sehingga lapisan lendir atau biofilm tersebut menebal. Mikroorganisme tersebut nantinya membantu proses degradasi senyawa organik pada air limbah [16]. Setelah dari bak biofilter anaerob, air limbah akan mengalir menuju bak biofilter aerob untuk penguraian zat organik oleh mikroorganisme dengan bantuan oksigen. Suplai oksigen untuk mikroorganisme diperoleh dari aerator yang menghasilkan gelembung udara yang menyebabkan terjadinya proses flotasi zat organik yang selanjutkan akan diendapkan pada bak sedimentasi akhir [7].

\section{Kesimpulan}

Proses pengolahan air limbah domestik pada IPAL Domestik INBIS Permata Bunda untuk air limbah grey water memiliki efektivitas reduksi berkisar antara 56,73\%-97,65\% dan telah memenuhi baku mutu untuk parameter pH, BOD, COD, Amoniak, minyak lemak dan Total Coliform. Namun, untuk nilai parameter TSS dan Total Coliform cenderung masih memerlukan evaluasi operasional IPAL agar lebih optimal, sehingga memenuhi baku mutu yang dipersyaratkan. Air limbah domestik grey water dari hasil pengolahan IPAL Domestik INBIS berpotensi menjadi sumber air alternatif untuk penyiraman tanaman (penghijauan) jika hasil pengolahan telah sesuai dengan baku mutu.

\section{Ucapan Terima Kasih}

Author mengucapkan terima kasih kepada Departemen Corporate Social Responsibility (CSR), PT. Pupuk Kaltim (PKT), Bontang dan Inkubator Bisnis Permata Bunda, Bontang yang telah membantu terlaksananya penelitian ini.

\section{Referensi}

[1] Badan Standar Nasional, Metode Pengambilan Contoh Air Limbah, BSN, Jakarta, 2008.

[2] M. Busyairi, Y.P. Dewi, dan D.I. Widodo, "Efektivitas Kaporit pada Proses Klorinasi terhadap Penurunan Bakteri Coliform dari Limbah Cair Rumah Sakit X Samarinda," Jurnal Manusia dan Lingkungan, PSLH UGM, 156-162, 2016. 
[3] R. Christiana, I.M. Anggraini, dan H. Syahwanti, "Analisis Kualitas Air dan Status Mutu serta Beban Pencemar Sungai Mahap di Kabupaten Sekadau Kalimantan Barat," Jurnal Serambi Enggineering, 941-950, 2020.

[4] E. Eriksson, K. Auffarth, M. Henze, and A. Ledin, Characteristics of Grey Wastewater, Denmark: UrbanWater, 2002.

[5] N. Hariyani dan S. Sarto, "Evaluasi Penggunaan Biofilter Anaerob-Aerob untuk Meningkatkan Kualitas Air Limbah Rumah Sakit," BKM Journal of Community Medicine and Public Health, 199204, 2018.

[6] Y. Kusumawardani, S. Subekti, dan Soehartono, "Potensi dan Pengaruh Batang Pisang sebagai Media Filter pada Pengolahan Air Limbah Pencucian Kendaraan bermotor," Jurnal Presipitasi, 196-204, 2019.

[7] E.U. Lolo \& Y.S. Pambudi, "Penurunan Parameter Pencemar Limbah Cair Industri Tekstil secara Koagulasi Flokulasi (Studi Kasus: IPAL Kampung Batik Laweyan, Surakarta, Jawa Tengah, Indonesia)," Jurnal Serambi Engginering, 1090-1098, 2020.

[8] D. Nababan, S.M.E. Juniati, I.E. Purba, N.E. Brahmana dan E.M. Silitonga, "Kemampuan Biofilter Anaerob berdasarkan Jenis Media dalam Pengolahan Air Limbah Domestik Tahun 2016," Jurnal Riset Hesti Medan Akper Kesdal I/BB Medan, 105-112, 2019.

[9] Peraturan Menteri Lingkungan Hidup dan Kehutanan, Baku Mutu Air Limbah Domestik No. P.68 Tahun 2016, Kementerian Lingkungan Hidup dan Kehutanan RI, Jakarta, 2016.

[10] S. Qomariyah \& F.R.D Kusumasari, "Perencanaan Bangunan Pengolahan Grey Water Rumah Tangga dengan Lahan Basah Buatan dan Proses Pengolahannya," e-jurnal Matriks Teknik Sipil, UNS, 939-945, 2016.

[11] A.N. Sidhi, M. Raharjo dan D.N.A. Yunita, "Hubungan Kualitas Sanitasi Lingkungan dan Bakteriologis Air Bersih terhadap Kejadian Diare pada Balita Wilayah Kerja Puskesmas Adiwerna Kabupaten Tegal," Jurnal Kesehatan Masyarakat, 665-676, 2016.

[12] A. Sumantri \& M.R. Cordova, "Dampak Limbah Domestik Perumahan Skala Kecil terhadap Kualitas Air Ekosistem Penerimanya dan Dampaknya terhadap Kesehatan Masyarakat," Jurnal Pengelolaan Sumberdaya Alam dan Lingkungan, 127-134, 2011.

[13] D.J. Susanthi, M.Y. Purwanto dan Suprihatin, "Evaluasi Pengolahan Air Limbah Domestik dengan IPAL Komunal di Kota Bogor," Jurnal Teknologi Lingkungan, 229-238, 2018.

[14] S. Yudo, S.\& Said, N. I. 2018. Studi Kasus Air Sungai Ciliwung di Wilayah DKI Jakarta. Jurnal Teknologi Lingkungan, 13-22.

[15] S. Yudo \& N.I. Said "Masalah Pencemaran Air di Jakarta, Sumber dan Alternatif Penanggulangannya," Jurnal Teknologi Lingkungan, 199-206, 2001.

[16] T. Zaharah, Nurlina, dan Moelyani, R., "Reduksi Minyak, Lemak dan Bahan Organik Limbah Rumah Makan Menggunakan Grease Trap Termodifikasi Karbon Aktif," Jurnal Pengelolaan Lingkungan Berkelanjutan, 23-32, 2017. 